Sybelle de Souza Castro Miranzi

Aidê A. Coelho dos Santos Gaspar ${ }^{2}$

Helena Hemiko Iwamoto ${ }^{3}$

Mário Alfredo Silveira Miranzi ${ }^{4}$

Daniel Cavarette Dziabas ${ }^{5}$

\section{Acidentes de trabalho entre os trabalhadores de uma universidade pública}

\author{
Work accidents among workers of a public university
}

\footnotetext{
${ }^{1}$ Enfermeira. Mestra e Doutora pela Escola de Enfermagem de Ribeirão Preto da Universidade São Paulo (EERP da USP). Professora Adjunta do Departamento de Medicina Social da Universidade Federal do Triângulo Mineiro (UFTM), Uberaba-MG.

${ }^{2}$ Enfermeira. Mestra e Doutoranda da FCM da Unicamp. Professora Assistente do Instituto de Ciências da Saúde da Universidade Paulista.

${ }^{3}$ Enfermeira. Mestra e Doutora pela EERP da USP. Professora Adjunta do Centro de Graduação em Enfermagem da UFTM.
}

${ }^{4}$ Cirurgião Dentista. Mestre e Doutor pela Universidade de Campinas (Unicamp). Professor Adjunto do Departamento de Medicina Social da UFTM.

${ }^{5}$ Aluno do Curso de Graduação em Medicina da UFTM.

Contato:

Helena Hemiko Iwamoto

Av. Santos Dumont, 1685, ap. 600

Uberaba, Minas Gerais.

CEP 38.050-400

E-mail:

iwamotokato@uol.com.br

\begin{abstract}
Resumo
O estudo teve como objetivo descrever os acidentes de trabalho ocorridos entre os trabalhadores do regime jurídico único e celetista. Trata-se de um estudo descritivo utilizando como fonte de dados a estatística anual do Setor de Ocorrência de Acidentes de Trabalho de uma universidade pública federal, localizada no interior do estado de Minas Gerais. Os dados foram coletados no período entre 2000 e 2005, quando foram notificados 1.008 acidentes de trabalho. A maioria ocorreu no hospital universitário, entre trabalhadores de enfermagem $(69,94 \%)$, no contato com material perfurocortante e exposição de mucosa e pele $(60,32 \%)$. As partes mais atingidas do corpo foram os membros superiores $(61,14 \%)$ e, como conseqüência, $18,07 \%$ das pessoas foram afastadas do trabalho. Os resultados demonstram que a maior parte dos acidentes foi registrada como decorrente de falha pessoal (85\%), o que indica a necessidade de serem implementados novos métodos de análise de acidentes de trabalho para investigar suas reais causas.
\end{abstract}

Palavras-chave: acidentes de trabalho, saúde do trabalhador, hospital.

\begin{abstract}
The current research aims at characterizing work related accidents among workers under the Brazilian legal labor system for private and public organizations. The study was based on database (years 2000 to 2005) from an annual publication on work accidents issued by a Brazilian public university located in the countryside of the state of Minas Gerais. During the above mentioned period there were 1,008 reported work related accidents. Most of them happened at the University Hospital, among the nursing staff (69.94\%), in contact with sharp-edged material and mucouse and skin exposition (60.32\%). The most affected parts of the body were the superior limbs (61.14\%). As a consequence, $18.07 \%$ of the workers were unable to continue working. The results indicated that most of the accidents were registered as personal errors (85\%), what indicates the necessity to implement new methods on work accident analysis to investigate their real causes.
\end{abstract}

Keywords: work accidents, worker's health, hospital. 


\section{Introdução}

No Brasil, os acidentes de trabalho representam um número relevante dentre as causas externas atendidas em serviços de saúde. Em 2000, a taxa de mortalidade por acidentes de trabalho se manteve acima da média dos países da América Latina, só perdendo para os países da África e da Ásia (VILELA; IGUTI; ALMEIDA, 2004). O sub-registro de óbitos por acidentes de trabalho no país é alarmante, variando entre 81,9\% em Porto Alegre, 76\% no Paraná (LEE, 1999) e taxas menores em São Paulo, de 39\% a 45\% (WALDVOGEL, 2003).

Estudo realizado por Deslandes (1999) em dois hospitais municipais de emergência no Rio de Janeiro revelou uma proporção de $18,7 \%$ de acidentes de trabalho dentre as causas externas em um dos hospitais e 15\% em outro. Já as pesquisas realizadas no período de 1994 a 2004, no Brasil, mostram que, apesar da redução do número de mortes por acidentes de trabalho, bem como da morbidade, não houve variação da incidência anual de acidentes incapacitantes (SANTANA; NOBRE; WALDVOGEL, 2005). A queda da mortalidade e da morbidade no período analisado pode ser mais atribuída à conseqüência das mudanças do perfil produtivo, em especial ao aumento do setor terciário de serviços (WÜNSCH FILHO, 1999; LOOMIS et al., 2004), do que à redução dos riscos ocupacionais ou à melhoria da segurança nas condições de trabalho.

Essas proporções tornam-se alarmantes ao se considerar que a notificação de acidentes de trabalho no Brasil persiste limitada à Previdência Social e é feita através da Comunicação de Acidente de Trabalho (CAT) para empregados com carteira assinada, excluindo-se os demais trabalhadores que, em 2000, segundo o Instituto Brasileiro de Geografia e Estatística (IBGE), correspondem a 78,5\% da população trabalhadora (IBGE, 2002). Portanto, as questões referentes a acidentes de trabalho e doenças relacionadas ao trabalho têm sido da competência dos Ministérios do Trabalho, da Saúde, da Previdência e Assistência Social.

Historicamente, a Lei Orgânica de Saúde $n^{\circ}$ 8080/90 atribuiu ao Sistema Único de Saúde (SUS) a competência da atenção integral à Saúde do Trabalhador, que envolve as ações de promoção, vigilância e assistência à saúde (BRASIL, 1990). Já a Política Nacional de Saúde do Trabalhador estabelece a estrutura de rede integrada de informações em saúde do trabalhador, destacando a estratégia de compatibilização dos sistemas e bases de dados entre os Ministérios do Trabalho, da Previdência Social, do Meio Ambiente e da Saúde e institui a concepção do nexo epidemiológico para acidentes e doenças relacionadas ao trabalho (BRASIL, 2004).

Nos últimos anos, observamos um avanço no sistema de informações no âmbito do SUS, tais como a notificação compulsória dos acidentes, estímulo de registro dos acidentes fatais a partir das Declarações de Óbito (DO) no Sistema de Informações sobre Mortali- dade (SIM) ou a morbidade por acidentes de trabalho nas internações, através do Sistema de Informações Hospitalares (SIH) (CONCEIÇÃO et al., 2003). Atualmente, tenta-se implantar, no estado de Minas Gerais, os Centros de Referência em Saúde do Trabalhador e a notificação compulsória de Acidentes de Trabalho e Doenças Ocupacionais.

O estudo realizado por Carneiro (2000) reafirma que a melhor fonte de identificação do número de óbitos por acidentes de trabalho é o Boletim de Ocorrência. No entanto, estima-se um sub-registro de 56,6\% relativo às informações do SIM e ausência da emissão de CAT em 95,1\% dos casos elegíveis. Cordeiro et al. (2005), ao realizarem um inquérito populacional numa cidade do interior de São Paulo, estimaram subnotificação de acidentes de trabalho em 79,5\%. Relatam, ainda, a precariedade da notificação dos acidentes de trabalho e sugerem a necessidade de instituir um sistema de informação eficaz e que subsidie políticas públicas de prevenção de acidentes.

Além do sub-registro, que contribui para a análise inadequada do perfil de acidentes de trabalho no país (VILELA; IGUTI; ALMEIDA, 2004), soma-se a alta incidência de acidentes de trabalho, bem como mortalidade e letalidade, que podem ser um reflexo da permanência da precariedade das condições de trabalho, da regulamentação pouco efetiva dos ambientes de trabalho e da insuficiência da saúde pública na promoção de ações específicas na área da saúde do trabalhador (SANTANA; NOBRE; WALDVOGEL, 2005).

As investigações que envolvem a situação dos acidentes de trabalho da área da saúde, principalmente os alocados nas instituições públicas, são um meio eficaz para o planejamento dos riscos ocupacionais, a análise dos setores e horários em que mais ocorrem os acidentes, os profissionais mais expostos, a área do corpo vulnerável e a profilaxia adotada nestes casos.

A prática profissional na área hospitalar somada à relativa escassez de informações sobre a temática e, principalmente, de metodologias eficazes para a diminuição dos acidentes de trabalho neste âmbito específico desperta o interesse em analisar a situação dos acidentes de trabalho entre os funcionários do setor público. Neste contexto, tem-se por objetivo descrever os acidentes de trabalho entre os trabalhadores de uma universidade federal, segundo o tipo de acidente, o local e o horário de ocorrência, o tipo de vínculo, a atividade exercida pelos trabalhadores, a parte afetada, os fatores determinantes e se estes acidentes demandaram afastamento ou não do trabalho.

\section{Material e métodos}

Delineamento do estudo: trata-se de um estudo descritivo observacional.

Local: uma universidade de propriedade da União, localizada no Triângulo Mineiro, responsável pela for- 
mação acadêmica, realização de pesquisa científica e assistência à comunidade.

População do estudo: casos de acidentes de trabalho (AT) notificados pelos trabalhadores no Setor de Ocorrência de AT da instituição, perfazendo o total de 1.008 casos.

Coleta de dados: utilizou-se um instrumento elaborado pelos pesquisadores, que possibilitou a alimentação do banco de dados a partir dos registros obtidos no setor de Ocorrência de AT da instituição. As variáveis do estudo foram: tipo de vínculo empregatício; setor de ocorrência; função dos acidentados; setor de vinculação do acidentado; motivo do acidente; horário de ocorrência; tipo de acidente; parte do corpo atingida; afastamento do trabalho. Os dados coletados foram referentes ao período de $1^{\circ}$ de janeiro de 2000 a 31 de dezembro de 2005.

Aspectos éticos da pesquisa: o presente estudo foi desenvolvido de modo a garantir o cumprimento dos preceitos da Resolução 196/96 da Comissão Nacional de Ética em Pesquisa, com a aprovação da instituição pesquisada e do Comitê em Pesquisa da Universidade Federal do Triângulo Mineiro, Protocolo 726.

Análise de dados: para fins de análise, subdividiram-se os trabalhadores acidentados em duas categorias distintas: do Regime Jurídico Único (RJU) - modalidade de vinculação específica dos servidores públicos estatutários; e do regime celetista - modalidade em que a relação entre o trabalhador e a organização é regida pela Consolidação das Leis do Trabalho (CLT). Apesar desta diferenciação, em ambos os casos, os AT devem ser notificados pelos trabalhadores ao Setor de Ocorrência de AT. Sendo do regime CLT, a comunicação deve ser feita em 24 horas, por meio da Comunicação do Acidente de Trabalho (CAT). Os trabalhadores do RJU têm um prazo de até dez dias após o ocorrido para fazer a comunicação do AT. Foi utilizada a análise descritiva a partir de freqüências absolutas e relativas e gerência dos dados no software Excel.

\section{Resultados}

No período de $1^{\circ}$ de janeiro de 2000 a 31 de dezembro de 2005, 1.008 trabalhadores comunicaram a ocorrência de acidentes de trabalho. Estes dados perfazem uma média de 14 acidentes de trabalho/ mês. Durante o período de 2000 a 2002 e 2005, foram notificados em média 12 a 13 acidentes por mês. O maior número de acidentes ocorreu nos anos de 2003 e 2004, atingindo a média de 18 e 17 acidentes de trabalho/mês, respectivamente.

A maior parte dos acidentes ocorreu com os trabalhadores do hospital universitário, sendo mais elevada entre os celetistas, 526 (52,18\%), quando comparada aos do RJU: 482 (47,82\%). Em termos proporcionais, os trabalhadores celetistas representam $1 / 3$ dos trabalhadores do RJU. Praticamente 2/3 dos acidentes ocorreram nas unidades de internação e no pronto socorro, 728 (72,22\%). Nos serviços ambulatoriais e de apoio diagnóstico ocorreram 154 (15,28\%) e nas áreas administrativas de ensino, pesquisa e extensão, 126 $(12,50 \%)$.

Nos anos de 2003 e 2004, ocorreu maior número de acidentes entre os servidores do RJU (Figura 1) quando comparada aos celetistas (Figura 2). Este fato coincide com o período de admissão de maior número de trabalhadores pelo RJU, o que pressupõe que houve maior freqüência de acidentes durante a fase de adaptação dos trabalhadores nos vários setores da área hospitalar. Na época, as precárias condições de infra-estrutura física e material de alguns setores, como o de internação médica, também podem ter contribuído para o aumento de acidentes. A redução de acidentes de trabalho em 2005 pode ser resultante da implantação do programa de prevenção de acidentes, a partir de 2004, com destaque para as atividades desenvolvidas pelo serviço especializado em segurança e medicina do trabalho.

Em relação às categorias profissionais acometidas, $2 / 3$ dos acidentes de trabalho foram notificados pelos trabalhadores de enfermagem: 705 (69,94\%). Os auxiliares de enfermagem sofreram 440 (43,65\%) acidentes, os técnicos, 224 (22,22\%) e os enfermeiros, $41(4,07 \%)$. Há que se destacar que os trabalhadores de enfermagem prestam assistência direta aos pacientes praticamente em toda a sua jornada de trabalho, demandando maior exposição aos riscos biológicos, quando comparados com outras categorias profissionais, e, conseqüentemente aos acidentes com material perfurocortante. Na universidade em questão, a maior proporção de acidentes de trabalho ocorreu durante o período diurno, 811 (80,54\%), sendo 453 (44,99\%) na parte da manhã (das 6 h30 às 12h30) e 358 (35,55\%) na parte da tarde (das $12 \mathrm{~h} 31$ às 18h29). Embora em menor número, houve registros de acidentes com trabalhadores do período noturno, 162 (16,09\%), e com os que trabalham especificamente nos horários administrativos, 19 (1,89\%), que compreende o horário das $8 \mathrm{~h}$ às $18 \mathrm{~h}$. Não constava a informação do horário dos acidentes em 16 (1,5\%) notificações. O fato dos acidentes ocorrerem em maior proporção no período diurno e entre os trabalhadores de enfermagem pode ser resultante da realização de um maior número de procedimentos de rotina, do maior número de profissionais de enfermagem lotados neste horário ou ainda da sobrecarga de trabalho imposta por falta de pessoal.

Entre 2000 e 2003, além de ocorrer maior freqüência de acidentes no período diurno, os acidentes com os celetistas (Figura 4) foram superiores aos dos servidores do RJU (Figura 3). Em 2004, observou-se uma inversão desta trajetória, com aumento de acidentes com os servidores do RJU e redução dos celetistas. Esta mudança pode estar atrelada à admissão de servidores com RJU, em especial da área de enfermagem (responsáveis por aproximadamente 70\% dos aciden- 
tes), que começaram a trabalhar durante o dia para conhecer as diversas rotinas de cada setor.

Ao considerar os tipos de acidentes ocorridos nesta universidade, os mais comuns foram de contato com material perfurocortante e exposição de mucosa e pele: 608 (60,32\%). Os acidentes decorrentes de esforço físico, queda, entorse, lombalgia, cervicalgia e impacto totalizaram 244 (24,21\%) e os de trajeto, 74 (7,34\%). Em 2003 e 2004, houve aumento de acidentes com material perfurocortante e exposição de mucosa notificados pelos servidores do RJU (Figura 5) e redução de acidentes pelos servidores celetistas (Figura 6), fato este que também coincide com a admissão de novos trabalhadores do RJU.

Marziale e Rodrigues (2002) referem que, ao analisar especificamente o trabalho realizado nos hospitais, percebe-se uma preocupação dos trabalhadores apenas com a exposição ao material biológico no cuidado com pacientes considerados de maior risco de contaminação, em especial com a Síndrome da Imunodeficiência Adquirida (Aids) e Hepatites B e C. Por outro lado, há que se destacar que os trabalhadores

\begin{tabular}{|l|c|c|c|c|c|c|c|c|c|c|c|}
\hline & \\
\hline
\end{tabular}

Figura 1 Frequiência da categoria profissional de acidentes de trabalho notificados pelos servidores do RJU, de 2000 a 2005. Uberaba, 2008
Figura 2 Frequiência da categoria profissional de acidentes de trabalho notificados pelos celetistas, de 2000 a 2005 . Uberaba, 2008

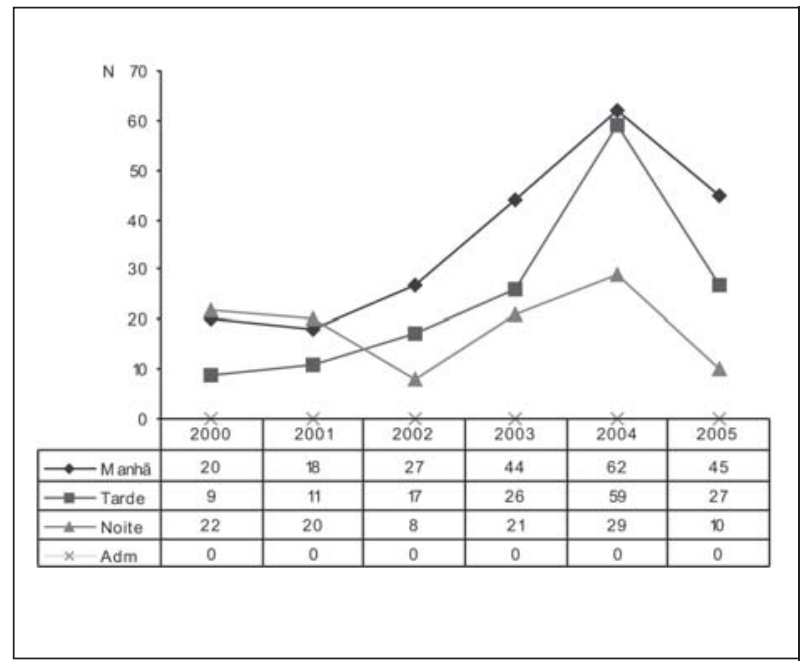

Figura 3 Frequiência do horário de ocorrência de acidentes de trabalho notificados pelos servidores do RJU, 2000 a 2005. Uberaba, 2007

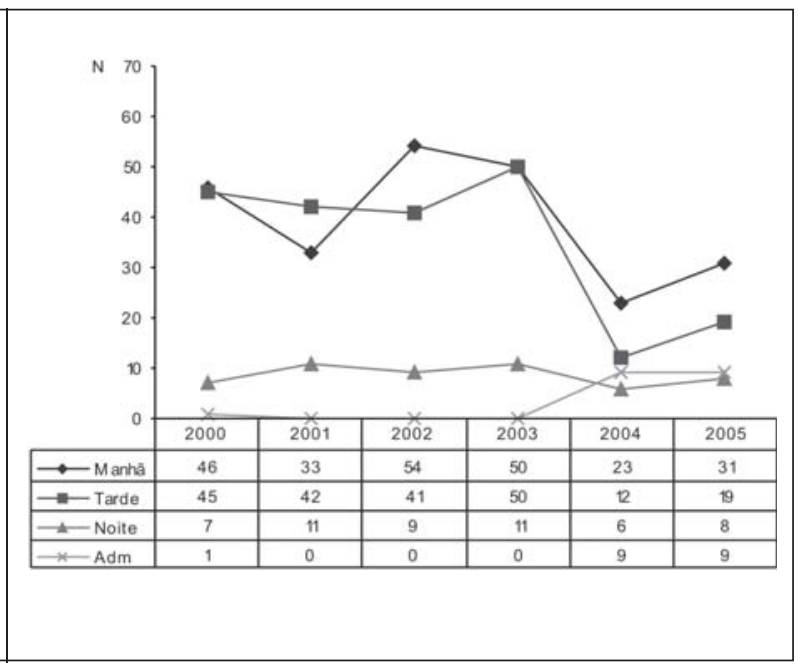

Figura 4 Frequiência do horário de ocorrência de acidentes de trabalho notificados pelos celetistas (CLT), de 2000 a 2005. Uberaba, 2007 
de enfermagem são vítimas de um maior número de acidentes justamente por realizarem procedimentos invasivos e pelo risco biológico a que estão sujeitos.

Em torno de 85\% das notificações de acidentes de trabalho foram referidas como falha pessoal (Figuras 7 e 8), sendo $620(61,63 \%)$ durante a manipulação e ao desprezar o material e $217(21,57 \%)$ por se encontrarem numa situação de insegurança técnica ou ocasionada por outras pessoas. Apenas 65 (6,46\%) descreveram falta de uso do equipamento de proteção individual e 104 (20,34\%) foram registrados como ausência de falha pessoal ou técnica. Esses dados demonstram que a instituição em questão ainda realiza suas ações na lógica da culpabilização da vítima (VILELA; IGUTI; ALMEIDA, 2004; OLIVEIRA, 2007).

Os dados levantados nesta universidade indicam que a maior parte das pessoas que se acidentaram não foram afastadas do trabalho 815 (83,93\%) e que as partes do corpo mais atingidas foram os membros superiores 439 (61,14\%), seguidos da cabeça e da face 137 (19,08\%). O tronco, os membros inferiores e outras partes totalizaram 142 (19,78\%) (Figuras 9 e 10).

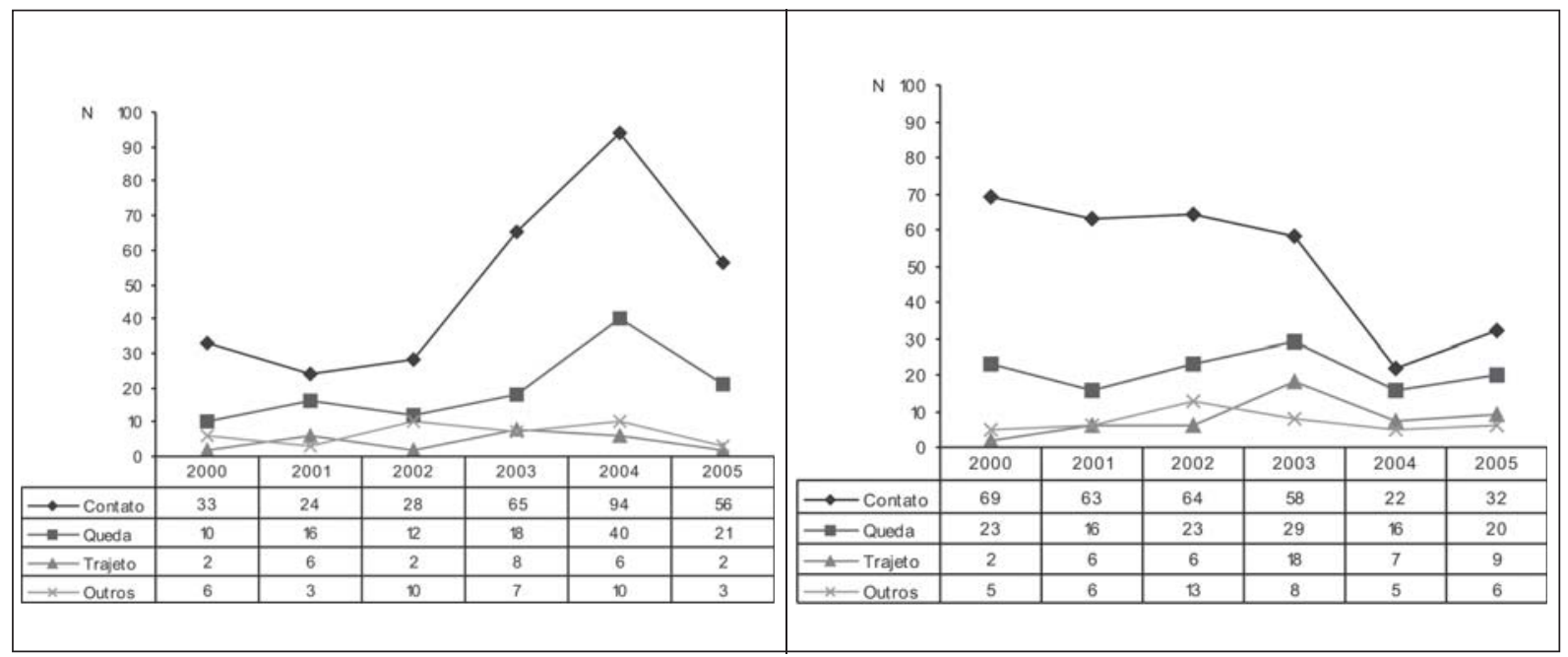

Figura 5 Frequiência do tipo de acidente de trabalho notificado pelos servidores do RJU, de 2000 a 2005. Uberaba, 2007
Figura 6 Frequiência do tipo de acidente de trabalho notificado pelos celetistas, de 2000 a 2005. Uberaba, 2007

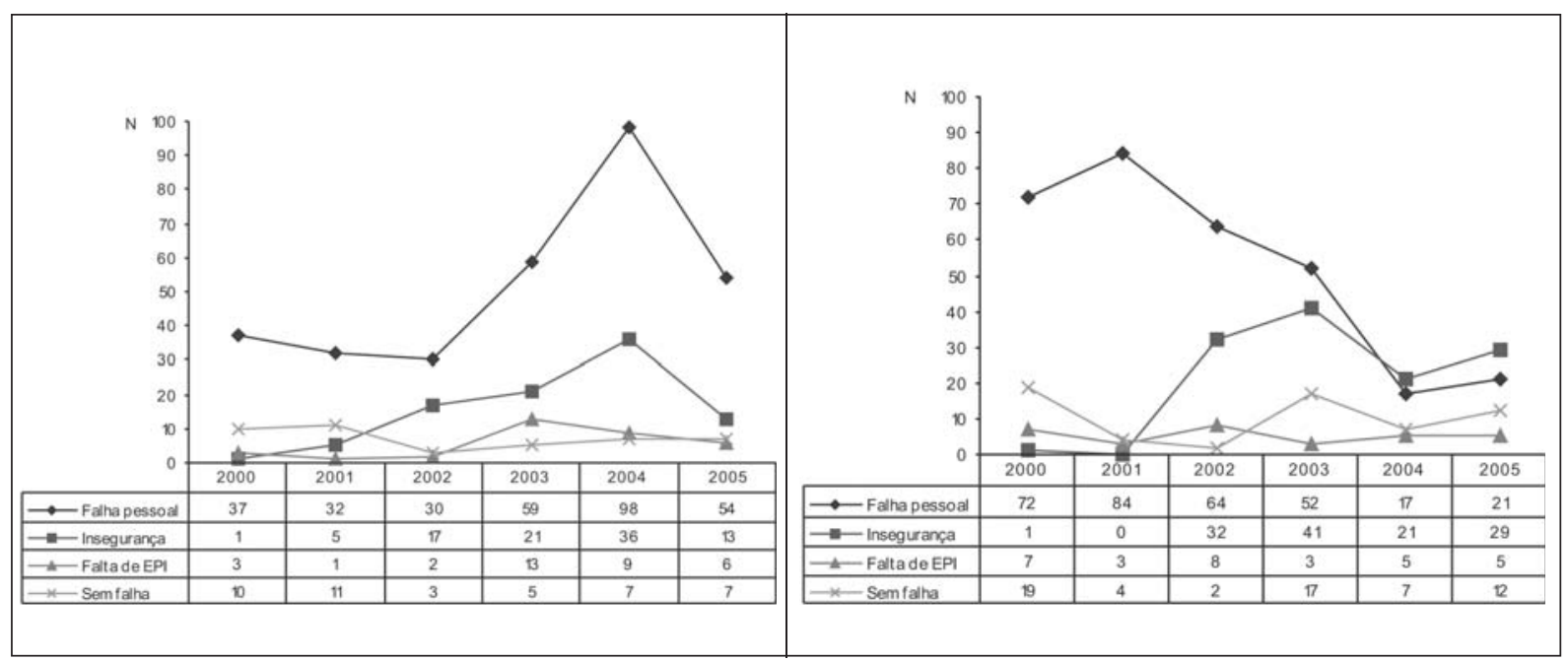

Figura 7 Frequiência do motivo de acidente de trabalho dos servidores do RJU, 2000 a 2005. Uberaba, 2007
Figura 8 Frequiência do motivo de acidente de trabalho dos celetistas, de 2000 a 2005. Uberaba, 2007 


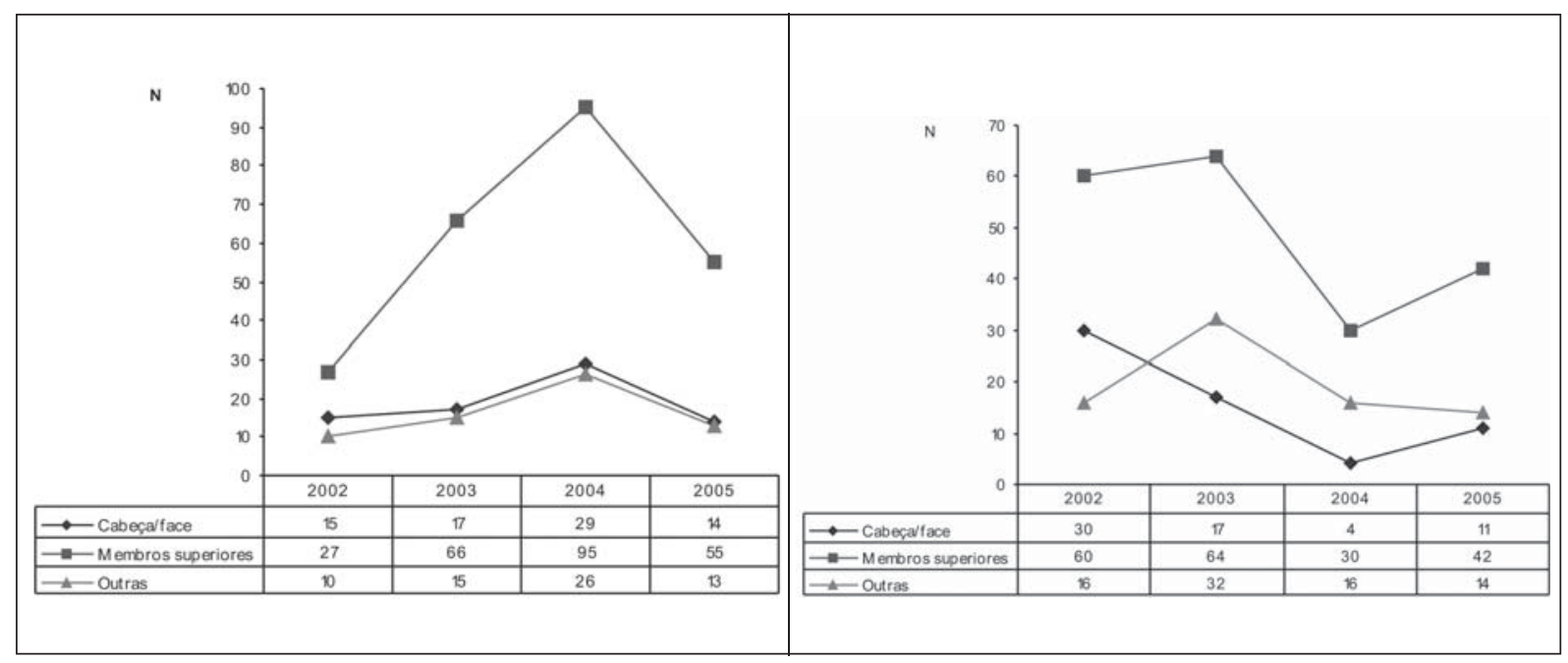

Figura 9 Parte do corpo atingida pelos acidentes de trabalho em servidores RJU, de 2002 a 2005. Uberaba, 2007

Figura 10 Parte do corpo atingida pelos acidentes de trabalho em celetistas, de 2002 a 2005. Uberaba, 2007

\section{Discussão}

De modo geral, os acidentes de trabalho ainda são vistos pelos trabalhadores sob a ótica monocausal, centrada na culpa da vítima, em que o empregador é isento de qualquer responsabilidade sobre o acidente. Muitas vezes, as reais causas dos acidentes ficam camufladas, dificultando a intervenção necessária para a realização de mudanças. Interferir na instituição significa, muitas vezes, ter que realizar várias mudanças no processo de trabalho, nas atividades em curso, nos meios produtivos e não apenas no comportamento do trabalhador (VILELA; IGUTI; ALMEIDA, 2004). É preciso refletir sobre a adequação do número de pessoas para cada atividade, as condições de trabalho, a área física, os materiais apropriados, a redução do estresse, melhores salários, a satisfação no trabalho e a qualidade de vida dos trabalhadores.

Somam-se, ainda, outras questões peculiares da profissão de enfermagem, que se constitui na sua maioria por mulheres e, no geral, com mais de uma jornada de trabalho, o que favorece o estresse, o cansaço e, por conseqüência, o aumento das possibilidades de acidentes. De modo geral, trabalhadores com menor nível de escolaridade apresentaram maior percentual de acidentes, corroborando com Murofuse, Marziale e Gemelli (2005) e Manetti et al. (2006).

$\mathrm{Na}$ área de saúde pode-se inferir que a elevação do número de acidentes não ocorre somente em função do maior manuseio de materiais perfurocortantes, mas talvez pela repetição das ações ou pelo volume de trabalho. Estudos como de Marziale et al. (2007) e Murofuse, Marziale e Gemelli (2005) demonstraram a maior ocorrência de acidentes em unidades de clínica médica, centro cirúrgico e pronto socorro, setores

com as respectivas características. Estratégias como a melhoria da qualidade de vida e das condições de trabalho através da reorganização do processo de trabalho podem gerar impactos positivos no número de acidentes, reduzindo os riscos ocupacionais e promovendo saúde para os trabalhadores (MARZIALE et al., 2007).

Estudo retrospectivo realizado por Canini, Gir e Machado (2005), com pessoal de apoio em um hospital do interior paulista, demonstrou que 96,8\% dos acidentes foram com materiais perfurocortantes e $76,9 \%$ receberam quimioprofilaxia, o que retrata a gravidade de acidentes que ocorrem nas instituições de saúde. Outras investigações destacam o risco de contaminação por acidente de trabalho no manuseio de materiais perfurocortantes e fluidos biológicos (MARZIALE; NISHIMURA; FERREIRA, 2004; OSÓRIO; MACHADO; MINAYO-GOMEZ, 2005) e o tipo de metodologia utilizado para análise de acidentes ocorridos no interior das instituições hospitalares (OSÓRIO; MACHADO; MINAYO-GOMEZ, 2005).

Os trabalhadores de um modo geral e os da área da saúde estão expostos ao risco de acidentes de trabalho, que podem ser: típicos, de trajeto ou doenças relacionadas ao próprio trabalho. Os acidentes de trajeto com os trabalhadores da universidade estudada ocorreram em 74 casos $(7,34 \%)$. Estes dados estão abaixo da média divulgada pelo Anuário Estatístico do Instituto Nacional de Seguridade Social (INSS, 2005) de 2005, que indica a ocorrência de 13,72\% de acidentes desta natureza no território nacional e $12,42 \%$ em Minas Gerais.

Vale destacar a observação da elevada freqüência de acidentes registrados como decorrentes de falha pessoal (85\%), perpetuando a idéia de culpabilização 
da vítima, referida em discursos de trabalhadores e estudos descritivos (VILELA; IGUTI; ALMEIDA, 2004; OLIVEIRA, 2007; VILELA; MENDES; GONÇALVES, 2007). No referido hospital, há uma ficha de notificação de acidente cujo campo para preenchimento dos motivos da ocorrência do acidente é composto por alternativas que incluem falha pessoal, não utilização de EPI, ocasionada por terceiros ou mesmo insegurança técnica, sem o campo para o motivo auto-referido pelo trabalhador. Torna-se importante a capacitação dos profissionais do Serviço Especializado em Segurança e Medicina do Trabalho (SESMT) desta instituição para a mudança de paradigma que é a transição da típica Medicina do Trabalho para a práxis da Saúde do Trabalhador.

Atualmente, os hospitais universitários realizam procedimentos de alta complexidade, que requerem a atuação de uma equipe altamente especializada de trabalhadores. No entanto, na área de enfermagem, o que se observa é uma constante escassez de profissionais. A prática cotidiana do pessoal de enfermagem tem sido marcada por diversas dificuldades que podem acarretar acidentes de trabalho e absenteísmo, conforme descrito por Silva e Marziale (2000). Essas dificuldades estão ligadas à falta de organização, à desmotivação, à repetitividade de ações e às más condições de trabalho, servindo como indicadores das condições de saúde dos trabalhadores.

\section{Conclusões}

Este estudo evidenciou uma elevada notificação de acidentes de trabalho, com variações entre 12 e 18 acidentes/mês no período de 2000 a 2005. A maior parte dos acidentes ocorreu no período diurno (80,54\%), com os trabalhadores de enfermagem $(69,94 \%)$ e do regime celetista $(52,18 \%)$.

Observou-se uma elevada freqüência de registros de acidentes como decorrentes de falha pessoal (85\%) e não por falta de equipamentos de proteção ou mes-

\section{Referências}

BRASIL. Ministério da Saúde. Secretaria de Atenção à Saúde. Departamento de Ações Programáticas e Estratégicas. Área Técnica de Saúde do(a) Trabalhador(a). Política nacional de saúde do trabalhador. Brasília, DF, 2004.

BRASIL. Lei nº 8080, de 19 de setembro de 1990. Lei orgânica da saúde. Diário Oficial [da] República Federativa do Brasil. Poder executivo, Brasília, DF, 20 set. 1990. Seção 2, p. 42

CANINI, S. R. M. S.; GIR, E.; MACHADO, A. A. Acidentes com material biológico entre trabalhadores dos serviços de apoio hospitalar. Rev. Latino-Am. mo más condições de trabalho. As partes mais atingidas do corpo foram os membros superiores $(61,14 \%)$, decorrentes do manuseio de material perfurocortante e da exposição de pele mucosa (60,32\%).

Apenas 18,07\% dos trabalhadores foram afastados do trabalho, o que pressupõe a ocorrência de acidentes considerados sem gravidade e pouco incapacitantes. Particularmente em relação aos trabalhadores de enfermagem, considera-se que, além do risco biológico decorrente do manuseio de materiais perfurocortantes, pode haver outros fatores associados às questões do processo e da organização do trabalho, como extensas jornadas de trabalho e estresse, entre outros, que evidenciam a necessidade de buscar mecanismos que retratem as reais causas dos acidentes nos hospitais universitários e o desenvolvimento de programas de prevenção.

Este estudo reflete a necessidade de maior aproximação com os aspectos que envolvem os acidentes de trabalho que ocorrem no cotidiano de um hospital universitário. Os resultados direcionam para a discussão de algumas questões que já vêm sendo feitas na instituição sobre como buscar mecanismos para a redução de acidentes de trabalho. As evidências demonstram que é preciso planejar e elaborar estratégias que possam prevenir a ocorrência de novos casos, principalmente em hospitais vinculados às universidades federais, onde há maior demanda de procedimentos de alta complexidade. É evidente, ainda, a responsabilidade do setor público em direcionar investimentos que resultem em segurança para os trabalhadores, com efetivos programas de saúde ocupacional.

Vale destacar a implantação, no início de 2007, de um novo sistema de notificação compulsória de acidentes de trabalho e doenças ocupacionais na universidade, que, atrelado às ações de vigilância epidemiológica, poderá contribuir para o monitoramento desses agravos e orientar medidas de controle e prevenção com base nas análises do Sistema de Informações de Agravos de Notificação.

Enferm., Ribeirão Preto, v. 13, n. 4, p. 496-500, jul./ ago. 2005.

CARNEIRO, S. A. M. Trabalho e violência: relação de proximidade da violência a trabalhadores durante a jornada de trabalho, na zona norte de São Paulo, em 1998. 2000. 149 f. Dissertação (Mestrado em Saúde Pública) - Faculdade de Saúde Pública, Universidade de São Paulo, São Paulo, 2000.

CONCEIÇÃO, P. S. A. et al. Acidentes de trabalho atendidos em serviço de emergência. Cad. Saúde pública, Rio de Janeiro, v. 19, n. 1, p. 111-117, jan./ fev. 2003. 
CORDEIRO, R. et al. Subnotificação de acidentes do trabalho não fatais em Botucatu, SP, 2002. Rev. Saúde pública, São Paulo, v. 39, n. 2, p. 254-260, abr. 2005.

DESLANDES, S. F. O atendimento às vitimas de violência na emergência: "prevenção numa hora dessas?”. Ci. Saúde col., Rio de Janeiro, v. 4, n. 1, p. 81-94, 1999.

IBGE. Pesquisa nacional por amostra de domicílios. Rio de Janeiro.RJ. IBGE, 2000. Disponível em: <http://www.ibge.gov.br>. Acesso em: 10 mar. 2002.

INSS. Anuário estatístico da Previdência Social. INSS, Brasília, 2005. Disponível em: <http://www.inss.gov. br/docs/pdf/aeps2005.pdf>. Acesso em: 10 mar. 2007.

LEE, J. B. Mortalidade por acidente de trabalho em Curitiba em 1998: uma análise crítica das declarações de óbito. 1999. 22f. Monografia. Universidade Federal do Paraná, Curitiba, 1999.

LOOMIS, D. et al. Deindustrialisation and the long term decline in fatal occupational injuries. Occup. Environ. Med., London, v. 61, n. 7, p. 616-621, July 2004.

MANETTI, M. L. et al. Prevenção de acidentes de trabalho com material biológico segundo o Modelo de Green e Kreuter. Rev. gaúcha Enferm., Porto Alegre, v. 27, n. 1, p. 80-91, mar. 2006.

MARZIALE, M. H. P.; RODRIGUES, C. M. M. A produção científica sobre os acidentes de trabalho com material perfurocortante entre trabalhadores de enfermagem. Rev. Latino-Am. Enferm., Ribeirão Preto, v. 10, n. 4, p. 571-577, jul./ago. 2002.

MARZIALE, M. H. P.; NISHIMURA, K. Y. N.; FERREIRA, M. Riscos de contaminação ocasionados por acidentes de trabalho com material perfurocortante entre trabalhadores de enfermagem. Rev. Latino-Am. Enferm., Ribeirão Preto, v. 12, n. 1, p. 36-42, jan./fev., 2004.

MARZIALE, M. H. P. et al. Acidentes com material biológico em hospital da Rede de Prevenção de Acidentes do Trabalho - REPAT. Rev. bras. Saúde ocup., São Paulo, v. 32, n. 115, p. 109-119, jan./jun. 2007.
MUROFUSE, N. T.; MARZIALE, M. H. P.; GEMELLI, L. M. G. Acidente com material biológico em hospital universitário do Oeste do Paraná. Rev. gaúcha Enferm., Porto Alegre, v. 26, n. 2, p. 168-79, ago. 2005.

OLIVEIRA, F. A persistência da noção de ato inseguro e a construção da culpa: os discursos sobre os acidentes de trabalho em uma indústria metalúrgica. Rev. bras. Saúde ocup., São Paulo, v. 32, n. 115, p. 19-27, jan./jun. 2007.

OSÓRIO, C.; MACHADO, J. M. H.; MINAYOGOMEZ, C. Proposição de um método de análise coletiva dos acidentes de trabalho no hospital. Cad. Saúde públ., Rio de Janeiro, v. 21, n. 2, p. 517-524, mar./abr. 2005.

SANTANA, V.; NOBRE, L.; WALDVOGEL, B. C. Acidentes de trabalho no Brasil: entre 1994 e 2004: uma revisão. Ci. Saúde col., Rio de Janeiro, v. 10, n. 4. p. 841-855, out./dez. 2005.

SILVA, D. M. P. P.; MARZIALE, M. H. P.

Absenteísmo de trabalhadores de enfermagem em um hospital universitário. Rev. Latino-Am. Enferm., Ribeirão Preto, v. 8, n. 5, p. 44-51, out. 2000.

VILELA, R. A. G.; IGUTI, A. M.; ALMEIDA, I. M. Culpa da vítima: um modelo para perpetuar a impunidade nos acidentes de trabalho. Cad. Saúde públ., Rio de Janeiro, v. 20, n. 2, p. 570-579, mar./ abr. 2004.

VILELA, R. A. G.; MENDES, R. W. B.; GONÇALVES, C. A. H. Acidente do trabalho investigado pelo CEREST Piracicaba: confrontando a abordagem tradicional da segurança do trabalho. Rev. bras. Saúde ocup., São Paulo, v. 32, n. 115, p. 29-40, jan./ jun. 2007.

WALDVOGEL, B. C. A população trabalhadora paulista e os acidentes de trabalho fatais. S. Paulo Perspec., São Paulo, v. 17, n. 2, p. 42-53, abr./jun. 2003.

WÜNSCH FILHO, V. Reestruturação produtiva e acidentes de trabalho no Brasil: estrutura e tendências. Cad. Saúde públ., Rio de Janeiro, v. 15, n. 1, p. 41-52, jan./ mar. 1999. 